\title{
Monitoring of Nutrient Status at Ratargul Swamp Forest in Sylhet, Bangladesh
}

\author{
Sabiha Akter, Md. Sirajul Islam*, Shamim Al Mamun \\ Department of Environmental Science and Resource Management, Mawlana Bhashani Science and \\ Technology University, Tangail-1902, Bangladesh \\ *Corresponding author (Email: islammstazu@yahaoo.com)
}

How to cite this paper: Akter, S., Islam, M.S. and Mamun, S.A. (2020). Monitoring of Nutrient Status at Ratargul Swamp Forest in Sylhet, Bangladesh. Grassroots Journal of Natural Resources, 3(1): 36-49. Doi: https://doi.org/10.33002/nr2581.6853.03014

Received: 21 January 2020

Reviewed: 29 February 2020

Provisionally Accepted: 04 March 2020

Revised: 17 March 2020

Finally Accepted: 19 March 2020

Published: 31 March 2020

Copyright (C) 2020 by author(s) and The Grassroots Institute.

This work is licensed under the Creative Commons Attribution International License (CC BY 4.0). http://creativecommons.org/licenses/by/4.0/
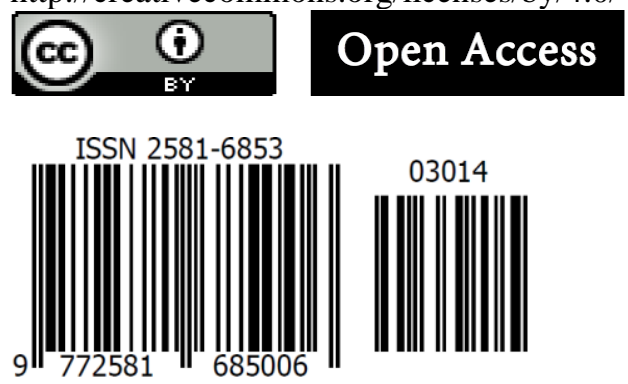

\begin{abstract}
Nutrient concentration is an important parameter to recognize critical processes of an ecosystem and environmental quality. This paper is based on a study carried out to evaluate the nutrient status in sediments, water and plant leaves from Ratargul swamp forest of Bangladesh during the period from September 2016 to August 2017. The samples were collected from twelve sampling stations of four different canals during dry (September 2016 to April 2017) and wet (May to August, 2017) seasons, respectively. The nutrient contents such as total nitrogen (TN), available phosphorus (AP) and total organic carbon (TOC) were analysed in the laboratory of the Bangladesh Institute of Nuclear Agriculture (BINA), Mymensingh, Bangladesh. The TN, AP and TOC in sediments were ranged from 2.22 to $5.23,0.032$ to 0.035 and 2.6 to $4.52 \%$, respectively, whereas TN and AP in water were found 5.34 to $22.54 \%$ and 0.002 to $0.366 \%$, respectively. Result showed that the TOC in plant leaves was higher in wet season than in dry season, where the TN and AP were higher in dry season than in wet season due to high temperature which increases the rate of photosynthetic activities in the dry season. In both Korochand Hijal plants, the TOC and AP were higher in green leaves than brown leaves, while TN was higher in brown leaves than green ones. Moreover, a statistically significant positive correlation was found among the samples. The study concluded that the nutrient status in sediments, water and leaves were perfectly natural during both the dry and wet season.
\end{abstract}

Keywords

Nutrient, Swamp forest, Sediments, Water, Plant leaves 
Doi: https://doi.org/10.33002/nr2581.6853.03014

\section{Introduction}

Freshwater swamps are the unique ecosystems having very specific vegetation. Water is the prime requisite for the vegetation of the swamp forests (Manhas et al., 2009). These forests are sites of natural succession and therefore contain all the groups of plant kingdom in a single place (Minar et al., 2013). Ratargul swamp forest is the only one freshwater swamp ecosystem in Bangladesh. Swamps play a vital role in landscaping with a wide variety of flora and fauna (Nahian et al., 2018). Due to variation in topography, a distinct floristic diversity is seen which is quite varied from the surrounding area (Sharma and Joshi, 2008). They support characteristic vegetation on account of specialized edaphic conditions, as influenced by free water accumulation (Gupta et al., 2006). They form integral part of the wetland ecosystems serving as habitats, nursery grounds and sources of food for many organisms (Brown et al., 1979). Forest swamp has important hydrological supportive functions including providing water storage space, adjusting and saving the flood peak, keeping the underground water level, recharging runoff, taking the degradation of pollution and purifying water quality (Xu and Chunjing, 2015). An ecosystem consists of plants, animals and microorganisms, which live in a definite zone along with the physical factors such as sediments, water and air; within an ecosystem, there are dynamic interrelationships between the living forms and their physical environment (Islam et al., 2016). This relationship is manifested as the natural nutrient cycles that provide a continuous circulation of the essential constituents necessary for sustaining the life processes in an ecosystem (De, 2010).

The swamp water has low $\mathrm{pH}$, nutrient levels and very low levels of anions and cations in the surface water, even lower than in the ground water. Nutrient deficient sediments retard plant growth. Therefore, plants growing on peat sediments must develop some specific mechanisms, such as organic acid exudation from roots to accumulate nutrients (Osaki et al., 2003). In general, plant species that grow and dominate in an ecosystem are affected by various environmental parameters causing differences in plant physiology, e.g. seed germination, relative growth rate, and competition with other plant species. They can also express the changes in the environmental development of an ecosystem (Omokhua and Koyejo, 2008). Nutrient concentration is used as an important parameter to recognize critical processes of an ecosystem. Nitrogen $(\mathrm{N})$ and phosphorus (P) are shown to control the rates of ecosystem processes and primary productivity in both aquatic and terrestrial ecosystems (Elser et al., 2007). The analysis of C, $\mathrm{N}$ and $\mathrm{P}$ stoichiometry in foliage and litter supports the hypothesis where the $\mathrm{N}$ is the major limiting nutrient in temperate regions while $\mathrm{P}$ tends to limit ecosystem productivity and processes in the tropical regions (Reich and Oleksyn, 2004). The objectives of the study were to investigate the concentration of total nitrogen (TN), available phosphorus (AP) and total organic carbon (TOC) in sediments, water and plant leaves of the forest and their inter relationship.

\section{Materials and Methods}

Study area: Ratargul swamp forest is located under the Gowainghat in Sylhet district, which is far about $45 \mathrm{~km}$ on the northwest of Sylhet town (Figure 1). The forest is situated on the bank of the river Gowain which has originated from the hilly areas of Meghalaya in India and falls into the Surma river (Choudhury et al., 2004). The total area of the swamp forest is 3325.61 acres (BFD, 2013). 


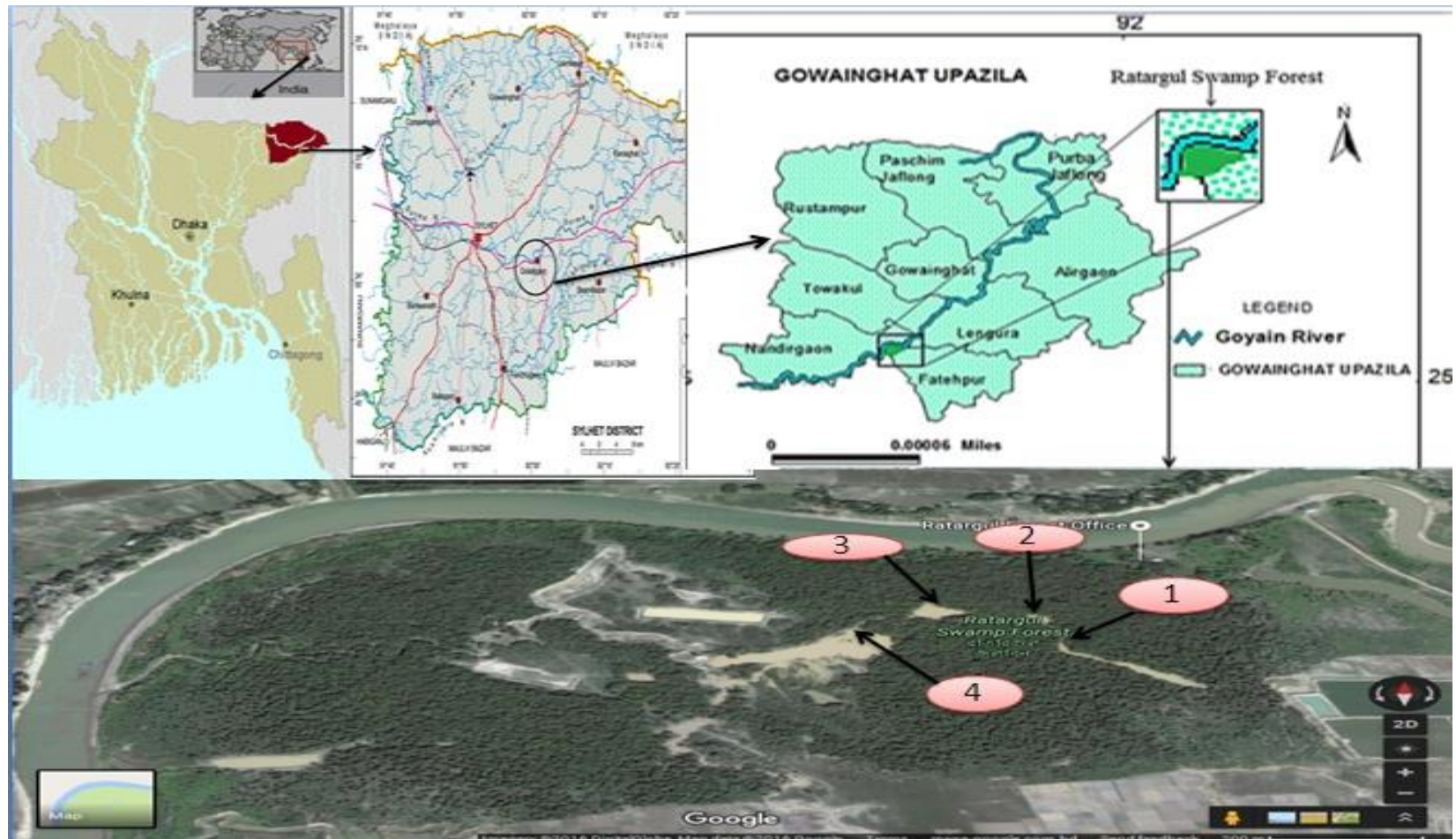

Figure 1: Map and images showing the study area in Ratargul swamp forest in Sylhet, Bangladesh (Banglapedia, 2016; Google Earth, 2017)

Sampling stations: The study was conducted for a period of 12 months from September 2016 to August 2017 at the Ratargul swamp forest. In this period, sediments, water and plant leaves were collected from four sampling stations (St). The St-1 (Athalur Khal) was situated behind the forest office where the forest comprises some bushes like Mukta (Clinogyne dichotoma, height 1.5 to 2 $\mathrm{m})$ as under-storey vegetation, Koroch (Pongamia pinnata, height 12 to $13 \mathrm{~m}$ ) and Hijal (Barringtonia acutangula, height 8 to $9 \mathrm{~m}$ ) as over-storey vegetation. The St-2 (Chirikurir Khal) was situated in the northwest of the St-1, where Koroch was the predominant tree species. The St3 (Horokuri Khal) was situated on northward of the St-2 and also crosses a dense stand of Mukta. The St-4 (Mendikuri Khal) was situated on southward to the St-3, where Koroch (12 to $14 \mathrm{~m}$ in height) was the predominant tree species.

Sample collection: A total of twelve (12) sediment samples were collected from four sampling stations in the forest. Samples were collected from surface (0 to $15 \mathrm{~cm}$ depth) at a distance of 0,10 and $20 \mathrm{~m}$ from the bank of water body in the dry season. The water samples were collected and measured seasonally over the year and on each sampling date. Three water samples were collected from each station. The Koroch (Pongamia pinnata) and Hijal (Barringtonia acutangula) are the dominant species of the forest. The green and brown leaves of Koroch and Hijal were used as sample for the study, collected seasonally over the year from each station.

Sample analysis: Collected samples of sediments, water and plant leaves were analysed in the laboratory of the Bangladesh Institute of Nuclear Agriculture (BINA), Mymensingh, Bangladesh. The total organic carbon (TOC) of the sediments and plant leaves samples were determined by Walkley and Black's wet oxidation method which was outlined by Jackson (1985). A wet-oxidation technique for determining total organic carbon in dry sediments and plant leaves, and aqueous plant 
leaves and sediments extracts is described as follows. The oxidation is carried out by heating the sediments or plant leaves samples with a mixture of potassium dichromate, sulphuric acid and phosphoric acid for 10-15 minutes, and the carbon dioxide liberated is determined gravimetrically after absorption in soda-lime (Shaw, 1959). The organic matter content was calculated by multiplying the content of organic carbon by Van Bemmelen's factor 1.73 (Piper, 1950). With slight modifications, the method has proved useful for the determination of carbon in plant extracts and would also appear suitable for a sediments extract. This method is much effective for the removal of carbonates without loss of organic carbon. It is proved that heating wet soil at $105^{\circ} \mathrm{C}$ causes considerable loss of organic carbon. Inert carbonaceous material, such as coal or charcoal, is oxidized by this wet-digestion method, thus producing erroneously high results for the carbon content of soil organic matter. This method is at least as accurate as the conventional drycombustion technique, and is less time-consuming, only one hour being required for determination (Shaw, 1959).

The total nitrogen (TN) was determined by Semi-micro Kjeldahl method by digesting sediments sample with concentrated $\mathrm{H}_{2} \mathrm{SO}_{4}$ and catalyst mixture $\left(\mathrm{K}_{2} \mathrm{SO}_{4}: \mathrm{CuSO}_{4} .5 \mathrm{H}_{2} \mathrm{O}\right.$ : $\left.\mathrm{Se}=10: 1: 0.1\right)$. Nitrogen in the digest was estimated by distillation with $40 \% \mathrm{NaOH}$ followed by titration of the distillate trapped in boric acid with $0.01 \mathrm{~N} \mathrm{H}_{2} \mathrm{SO}_{4}$ (Page et al., 1989). The percentage (\%) of $\mathrm{N}$ in sediments was calculated by the following equation:

$\% \mathrm{~N}=\frac{(R-B) * S * 1.4}{W}$

Where, $\mathrm{R}=$ Reading of the sample in burette $\left(\mathrm{H}_{2} \mathrm{SO}_{4}\right)$

$\mathrm{S}=$ Strength of $\mathrm{H}_{2} \mathrm{SO}_{4}$

$\mathrm{B}=$ Content of blank reading

$\mathrm{W}=$ Weight of the sediments

$1.4=$ Correction factor.

Available phosphorus (AP) was determined by Olsen's method (Iatrou et al., 2014) using $\mathrm{SnCl}_{2}$ as reducing agent. Five grams of sediments were taken in a $250 \mathrm{ml}$ conical flask. Then a little of carbon black and $100 \mathrm{ml}$ of $0.5 \mathrm{M} \mathrm{NaHCO}_{3}$ were added to it. The contents were then shaken for 30 minutes on a horizontal mechanical shaker and were filtered through Whatman no. 40 filter paper. Later, $5 \mathrm{ml}$ of extract was taken into a $50 \mathrm{ml}$ volumetric flask followed by $4 \mathrm{ml}$. A few drops of $\mathrm{SnCl}_{2}$ solution were also added and finally the volume was made up to the mark with distilled water and allowed to stand for 10 minutes to complete color development. The AP in the extract was then determined by developing a blue color by $\mathrm{SnCl}_{2}$ reducing of phosphomolybdate complex and measuring the color calorimetrically at $660 \mathrm{~nm}$ wavelength comparing the color developed with a standard phosphate solution (Black, 1965).

\section{Results and Discussion}

\section{Sediments nutrients}

Total organic carbon (TOC): The total organic carbon ranged from $2.6 \%$ to $4.52 \%$ in the surface sediments of Ratargul swamp forest, whereas the mean TOC content was $3.593 \%$. The highest TOC $(4.52 \%)$ content was found at St-1, while the lowest TOC content $(2.6 \%)$ was observed in the surface sediments at St-2 (Figure 2). 


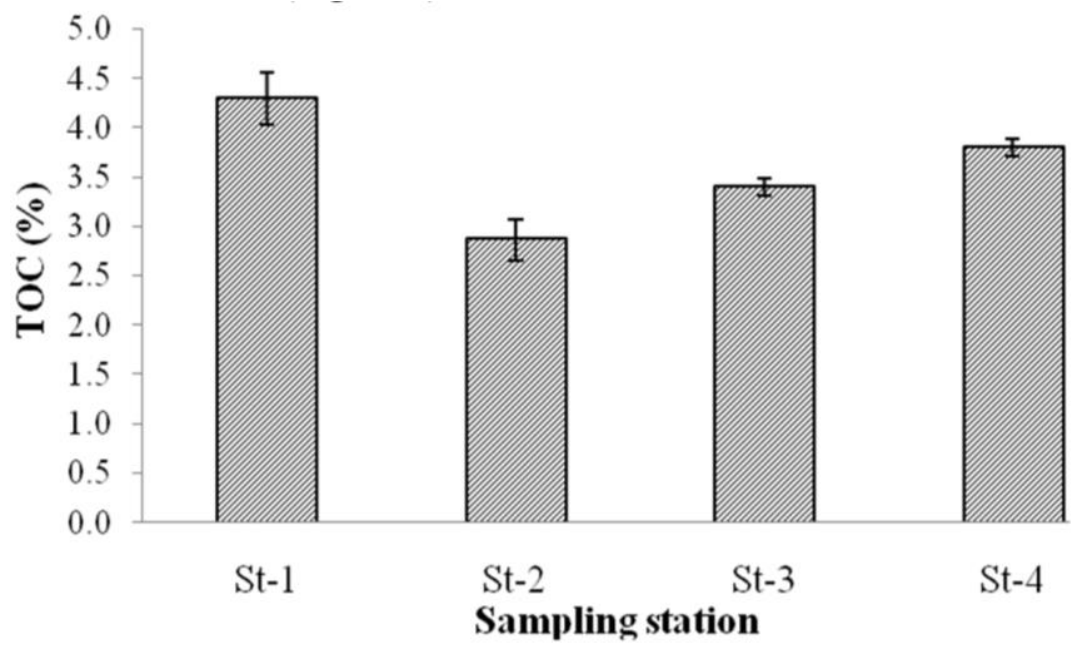

Figure 2: Status of TOC in sediments at different sampling stations at Ratargul swamp forest

The average TOC content in the surface sediments was $4.297,2.867,3.404$ and $3.803 \%$ at St-1, St2, St-3 and St-4, respectively. High amount of TOC content might be due to the forested depressions. A similar study was conducted for TOC contents (5.2\%) in sediments of wetland in Georgia, USA where the forested depressions were having significantly higher organic carbon (C) contents compared to the other wetlands (Craft and Casey, 2000).

Total nitrogen (TN): Total nitrogen content ranged from $2.221 \%$ to $5.23 \%$ in the surface sediments where the mean content was 3.339\%. Moreover, the highest TN $(5.23 \%)$ was found at St-3 and the lowest was observed at St-2 $-2.221 \%$ (Figure 3). The average TN contents in the sediments were $0.359,0.227,0.512$ and $0.257 \%$ at St-1, St-2, St-3 and St-4, respectively. The TN content in sediments of a wetland was $0.38 \%$, due to forested depressions significantly higher than other wetlands (Craft and Casey, 2000). High amount of nitrogen (N) in the sediments of Sundarbans mangrove forest was also found by a previous study (Hossain and Bhuiyan, 2016). The deposition and decomposition of huge quantities of solid wastes from the forest and surrounding area, and the use of $\mathrm{N}$ as a fertilizer in the agricultural land were found to be responsible for the enrichment of TN content in the sediments. This study concluded that nitrogen content in the sediments of the forest was suitable for growth of plant and microorganisms in the forest.

Available phosphorus (AP): Total phosphorus content ranged from $0.032 \%$ to $0.035 \%$, whereas mean content was $0.034 \%$. The highest and lowest AP contents were found to be 0.035 and $0.032 \%$ at St-3 and St-2, respectively (Figure 4). The average AP contents were 0.034, 0.032, 0.351 and $0.034 \%$ at St-1, St-2, St-3 and St-4, respectively. It is observed that phosphorus (P) contents were suitable for growth of plant and microorganisms in the forest. The AP content in the surface sediments of wetland was $0.034 \%$, which was significantly higher than other wetlands (Craft and Casey, 2000). Another study in Sundarbans mangrove forest revealed that there was high amount of phosphorous (P) in sediments (Hossain and Bhuiyan, 2016) due to deposition and decomposition of huge quantities of solid wastes in the forest and surrounding area. The use of $\mathrm{P}$ as fertilizer in the agricultural land may be responsible for the enrichment of AP in sediments. 


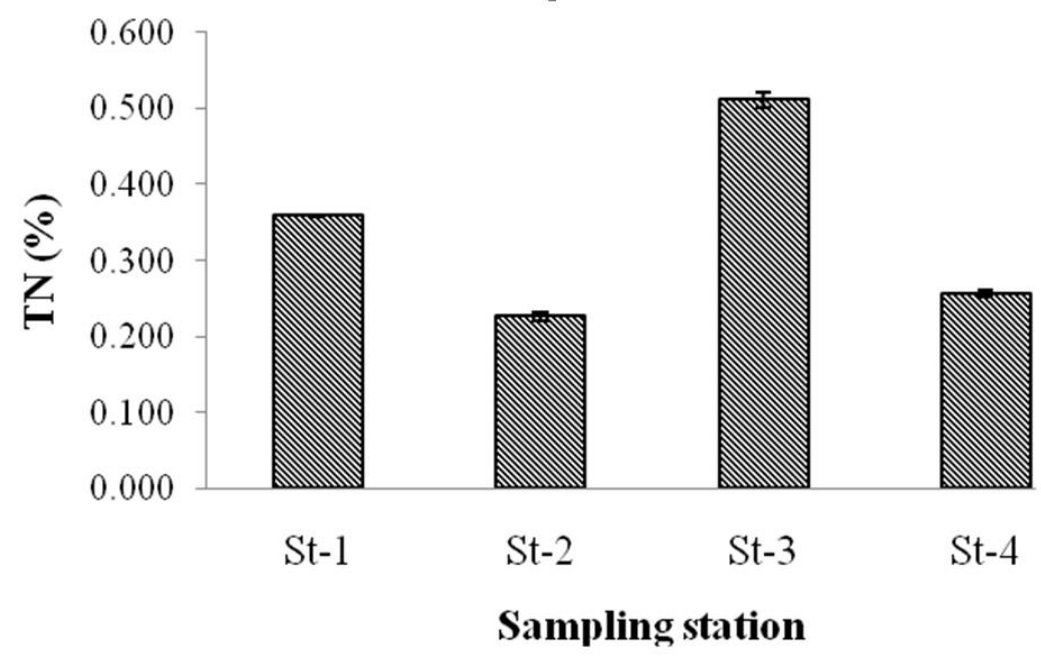

Figure 3: Status of TN in sediments at different sampling stations at Ratargul swamp forest

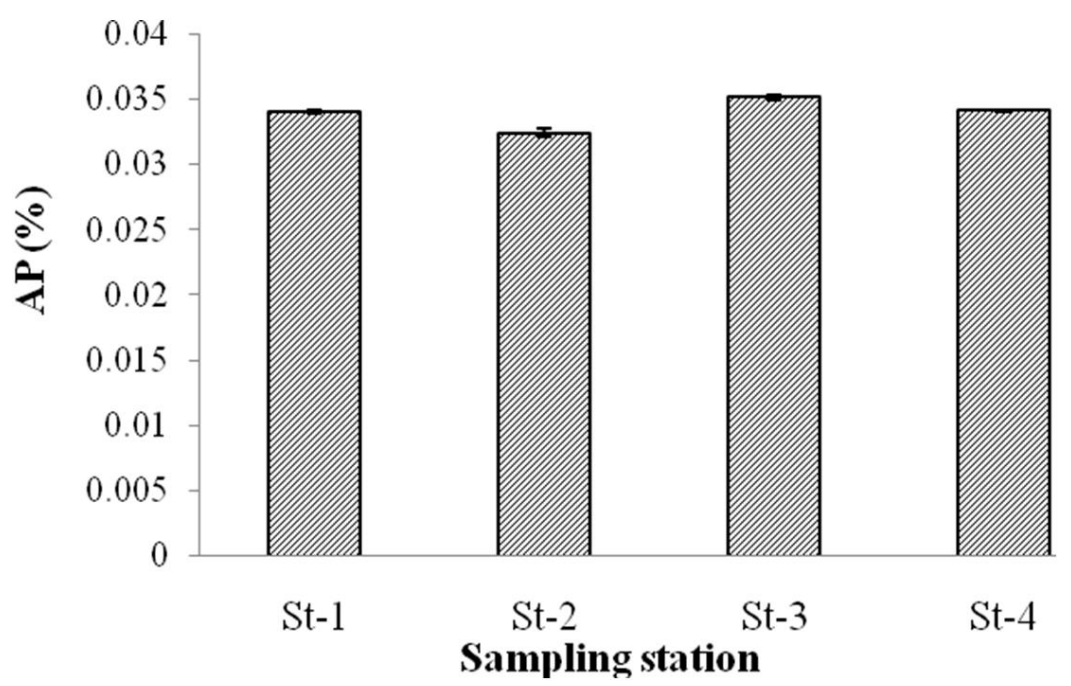

Figure 4: Status of AP in sediments at different sampling station of Ratargul swamp forest

\section{Water nutrients}

Total nitrogen $(\mathrm{TN})$ : There was a significant variation in total nitrogen content in dry and wet season $(\mathrm{P}>0.004, \mathrm{df}=3)$. Total nitrogen $(\mathrm{TN})$ contents ranged from $5.34 \%$ to $22.54 \%$ with a mean of $12.385 \%$. The highest TN content was found $22.54 \%$ at St-3 during the wet season, where the lowest content 5.34\% was found at St-2 during the dry season (figure 5). The average TN contents along the Ratargul swamp forest were 7.123, 6.057, 7.267 and 6.42\% at St-1, St-2, St-3 and St-4, respectively, in dry season, whereas, during the wet season the TN contents were 15.52, 15.37, 21.523 and $19.133 \%$ at St-1, St-2, St-3 and St-4, respectively. A study found that higher amount of $\mathrm{N}$ content in the wet season than the dry season is due to excessive use of nitrogen in the surrounding agricultural land and mixing of nitrogen with the water through the run off during the wet season (Hossain and Bhuiyan, 2016). 


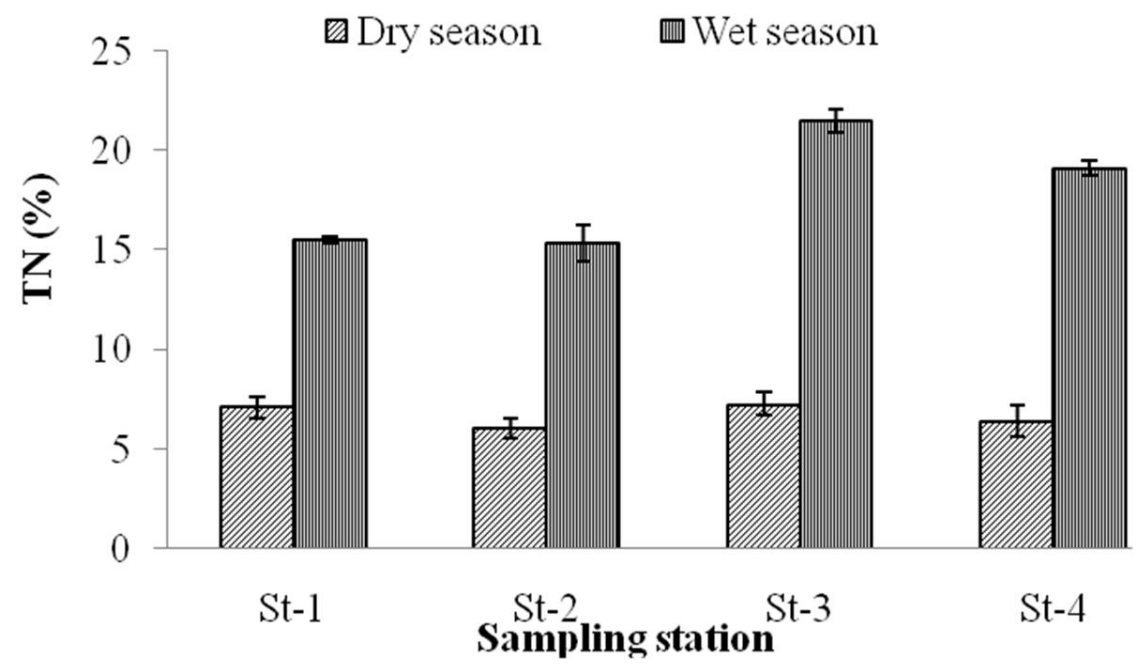

Figure 5: The TN of water in Ratargul swamp forest at different sampling season

Available phosphorus (AP): The available phosphorus (AP) contents ranged from $0.002 \%$ to $0.366 \%$ with a mean of $0.166 \%$, where significant variation of total phosphorus in dry and wet season $(\mathrm{P}>0.018, \mathrm{df}=3)$ was found. The highest AP content $0.366 \%$ was found at $\mathrm{St}-3$ during the wet season and the lowest was $0.002 \%$ at $\mathrm{St}-2$ during dry season (Figure 6). The average AP content along the Ratargul swamp forest was 0.027, 0.028, 0.068 and 0.047\% at St-1, St-2, St-3 and St-4, respectively, in dry season. However, during the wet season, the AP contents were 15.52, 21.523, 15.37 and $19.133 \%$ at St-1, St-2, St-3 and St-4, respectively. The study found that the amount of $\mathrm{TN}$ and AP were higher in the wet season than the dry season due to use of excessive nitrogen fertilizer in the surrounding agricultural land that in turn mixed with the water through the run off during the wet season (Hossain and Bhuiyan, 2016).

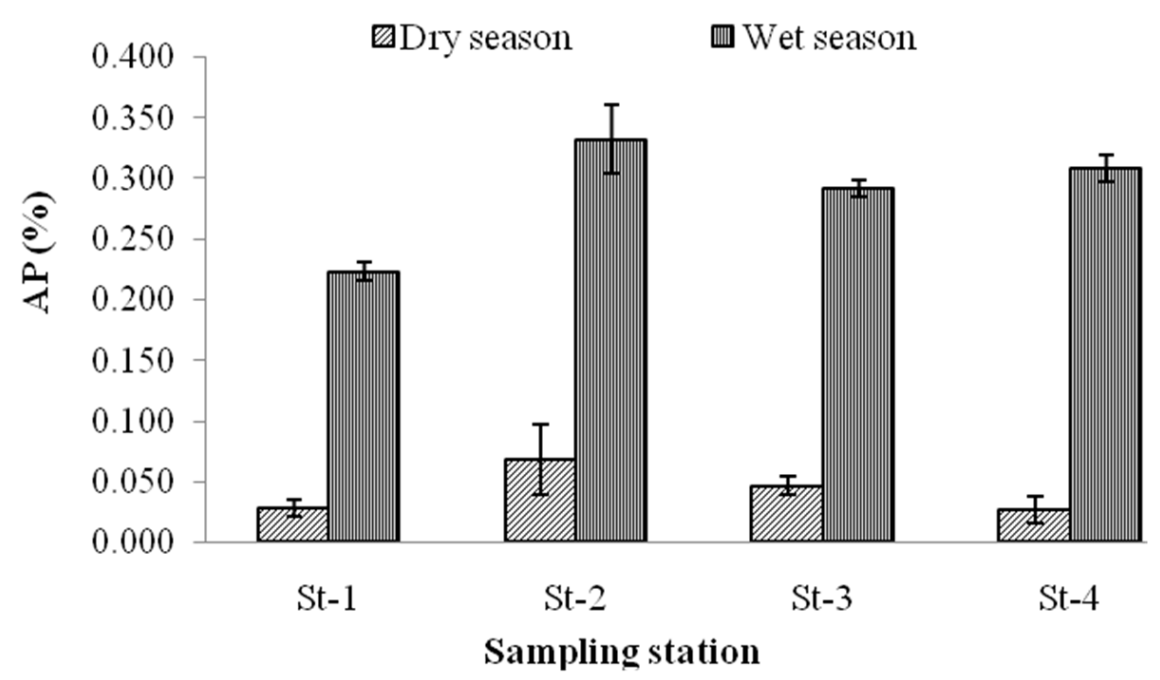

Figure 6: The AP of water in different sampling season Ratargul swamp forest 
Doi: https://doi.org/10.33002/nr2581.6853.03014

\section{Plant leaf nutrients}

Total organic carbon (TOC): The significant ( $>>0.003)$ variation of TOC in dry and wet season and in green and brown leaves ( $>>0.03)$ of Hijal were observed. Higher amount of TOC content $(48.887 \%)$ was found in green leaves at St-3 during wet season, while the lowest (36.57\%) was found in brown leaves at St-4 during dry season (Figure 7). The contents of TOC in green leaves of Hijal were 43.057 (St-1), 39.413 (St-2), 40.52 (St-3) and 43.11\% (St-4) during dry season and 45.587 (St-1), 43.760 (St-2), 48.887 (St-3) and 42.727\% (St-4) during wet season. In the brown leaves of Hijal, the contents of TOC were 41.13 (St-1), 38.523 (St-2), 36.903 (St-3) and 36.7\% (St4) during dry season, and 44.7 (St-1), 39.9 (St-2), 39.623 (St-3) and 39.897\% (St-4) during wet season. In Koroch leaves, there was no significant $(p>0.171)$ variation of TOC in dry and wet season but significant variation with $\mathrm{p}>0.04$ was found in green and brown leaves. The highest content of TOC was $53.977 \%$ at $\mathrm{St}-4$ in green leaves during wet season and the lowest amount was $42.233 \%$ at St-3 in brown leaves during the season (figure 8).
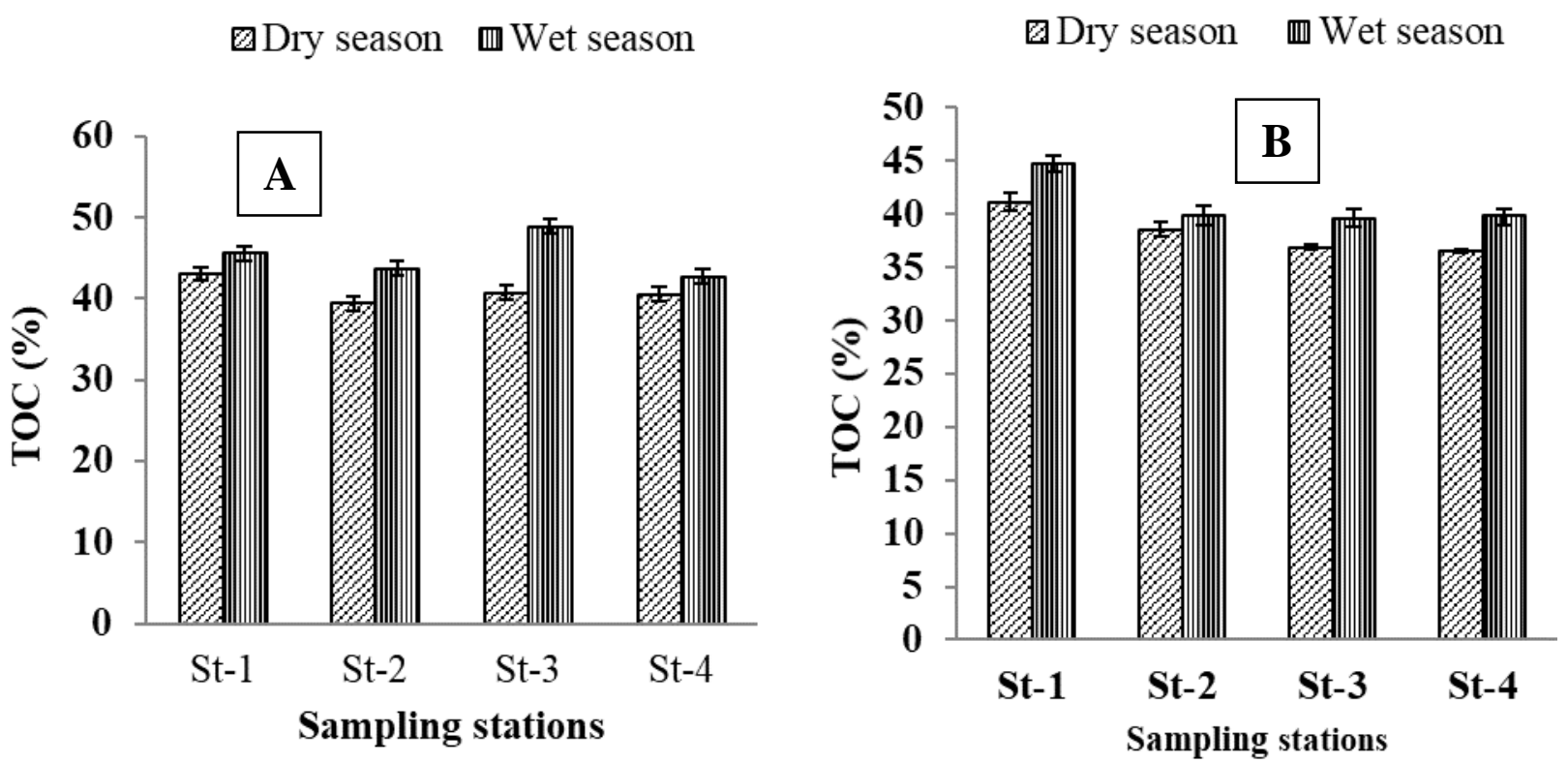

Figure 7: The TOC in green (A) and brown (B) leaf of Hijal plant in different sampling season

The TOC contents 46.223 (St-1), 44.493 (St-2), 43.247 (St-3) and 45.167\% (St-4) were found in green leaves during dry season, and 52.1, 53.643, 52.07 and 53.977\% were found in wet season at St-1, St-2, St-3 and St-4, respectively. In the brown leaves of Koroch, 44.24, 43.993, 42.233 and $43.057 \%$ of TOC were found during dry season and 50.1, 52.65, 50.05 and $53.133 \%$ were found during wet season at St-1, St-2, St-3 and St-4, respectively. The study found that average TOC in leaves was higher in the wet season than dry season which might be due to the higher temperature in wet season that increases the rate of photosynthetic activity. In both Koroch and Hijal, the TOC contents were higher in the green leaves than the brown. This might be due to the presence of chlorophyll in the green leaves. Similar study found that TOC contents depend on temperature and it increased when the temperature is increased (Reich and Oleksyn, 2004). 

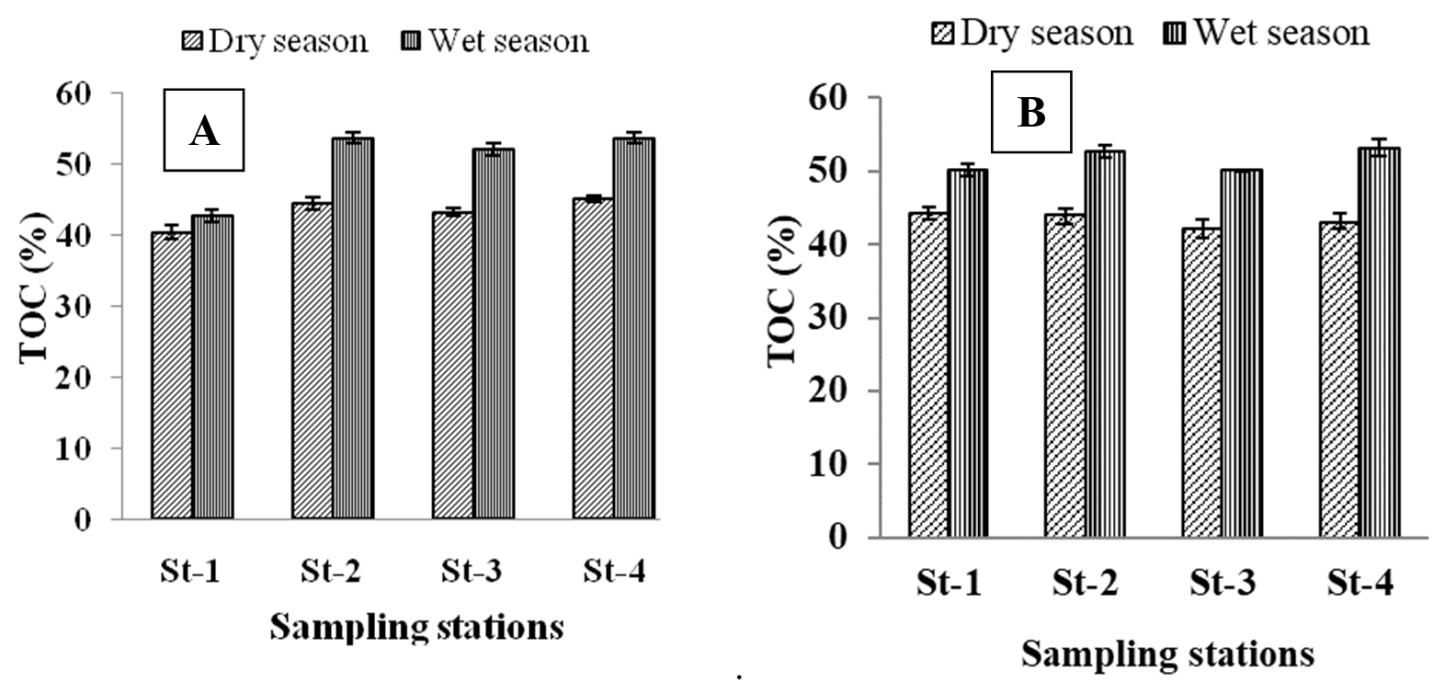

Figure 8: The TOC in green (A) and brown (B) leaf of Koroch plant in different sampling season

Total nitrogen $(\mathrm{TN})$ : Statistically significant $(\mathrm{p}>0.001)$ variation of TN was noticed in dry and wet season in both green and brown leaves $(p>0.03)$ of Hijal. In Hijal plant, higher content of TN was $5.02 \%$ in brown leaves at St-3 and St-1 during dry season, while the lowest $(1.20 \%)$ was in green leaves at St-3 during wet season. Contents of TN in green leaves of Hijal were 3.3, 3.0, 3.87 and $3.3 \%$ during dry season and 1.08, 1.07, 1.20 and 1.3\% during wet season at St-1, St-2, St-3 and St4, respectively (Figure 9). On the other hand, TN contents were 5.02, 3.85, 5.02 and $4.08 \%$ in brown leaves during dry season at St-1, St-2, St-3 and St-4, respectively, whereas the TN in brown leaves was $2.51 \%$ at St-1, 2.51\% at St-2, $1.36 \%$ at St-3 and $1.70 \%$ at St-4 during wet season. In the Koroch plant, there were significant $(\mathrm{p}>0.001$ and $\mathrm{p}>0.03)$ variations of $\mathrm{TN}$ at dry and wet season in green and brown leaves, respectively. The highest content of TN was 5.04\% at St-1 in brown leaves during dry season and lowest was $1.6 \%$ at St-1 in green leaves during wet season (Figure 10). TN contents were 2.73\% (St-1), 2.77 (St-2), 4.45 (St-3) and 2.69\% (St-4) in green leaves during dry season and 1.6 (St-1), 1.79\% (St-2), 1.86\% (St-3) and 1.79\% (St-4) were found in wet season. In brown leaves of Koroch, TN were 5.04, 3.93, 4.88 and 3.88\% during dry season and 2.01, 2.07, 2.03 and 2.08\% were found during wet season at St-1, St-2, St-3 and St-4, respectively. The TN contents in the plant leaves were higher in dry season than wet season, which might be due to the high temperature in wet season and temperature directly influences the physiological processes. In both Koroch and Hijal leaves, TN contents were higher in brown leaves than the green; it may be due to the presence of carotenoids in the brown leaves. The TN depends on the temperature and increased with the rising of temperature (Reich and Oleksyn, 2004). 

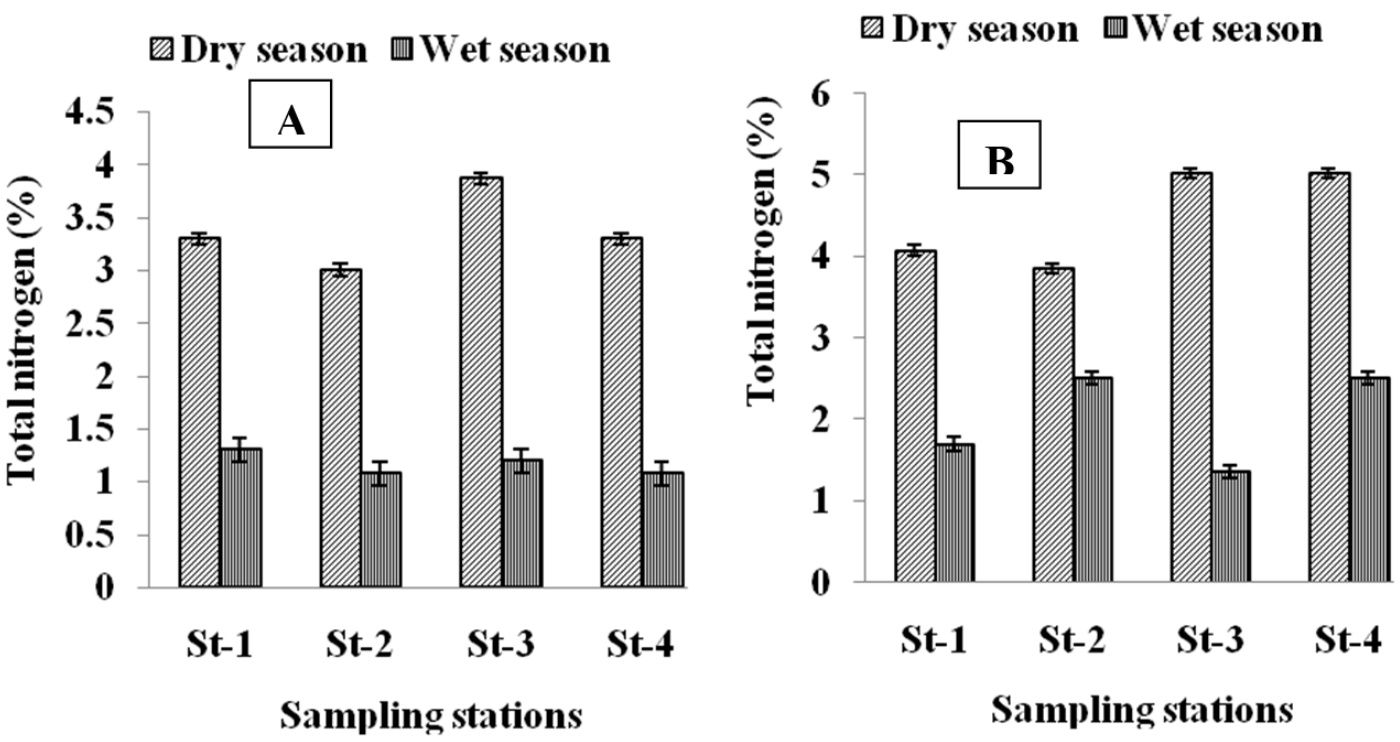

Figure 9. The TN in green (A) and brown (B) leaf of Hijal plant at different sampling season
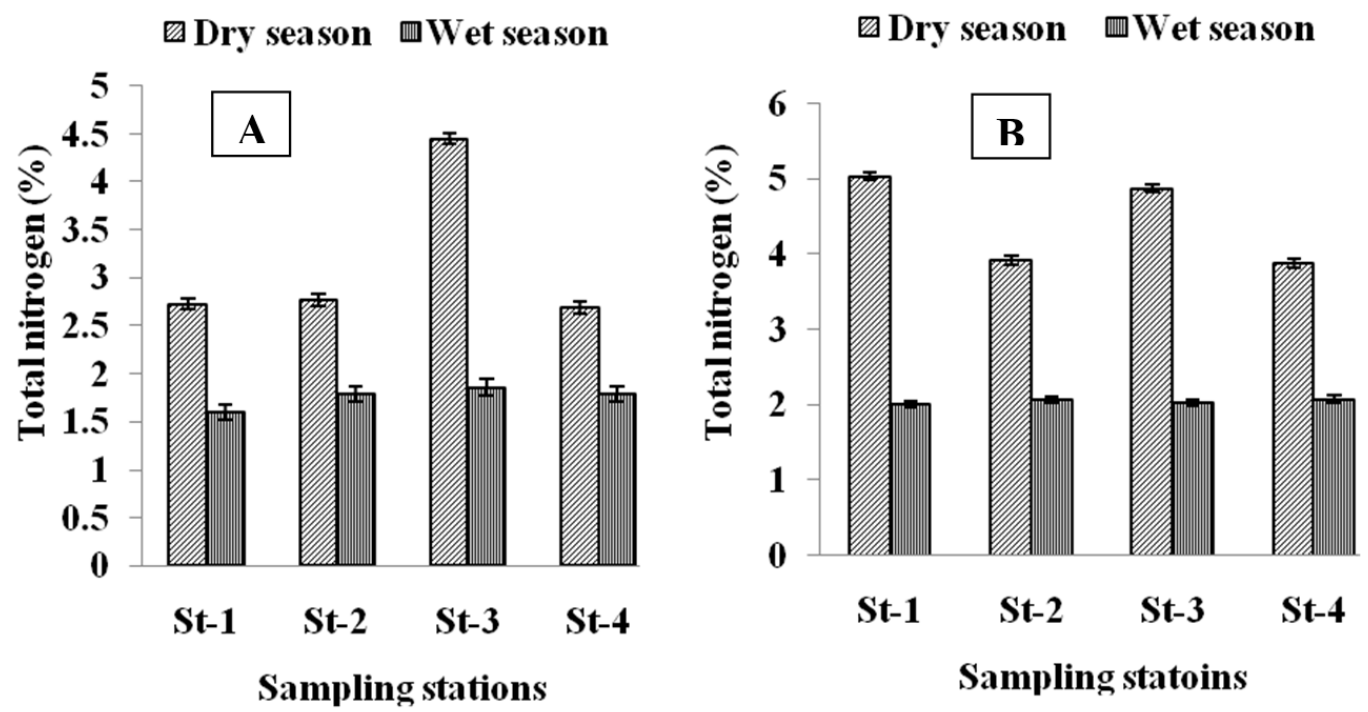

Figure 10. The TN in green (A) and brown (B) leaf of Koroch plant in different sampling season

Available phosphors (AP): There was significant ( $\mathrm{p}>0.008)$ variation of AP in dry and wet season, and in green and brown leaf ( $\mathrm{p}>0.001)$. In Hijal (B. acutangula) plant, higher $(0.126 \%)$ content of AP was found in green leaves at St-3 during dry season. However, the lowest content of AP $(0.025 \%)$ was found in the brown leaf at St-3 during wet season. Contents of AP in green leaves of Hijal were $0.102,0.11,0.126$ and $0.122 \%$ during dry season and $0.031,0.036,0.03$ and $0.053 \%$ during wet season at St-1, St-2, St-3 and St-4, respectively (Figure 11). The AP contents were 0.093, 0.086, 0.98 and $0.098 \%$ in brown leaves of Hijal during dry season at St-1, St-2, St-3 and St-4, respectively. During wet season, AP contents in brown leaves were 0.029\% at St-1, 0.039\% 
at St-2, $0.025 \%$ at St-3 and $0.041 \%$ at St-4. In the Koroch plant leaves, there was statistically significant $(\mathrm{p}>0.001)$ variation of AP in dry and wet season; however, a significant variation ( $p>0.002)$ was found in green and brown leaves. The highest content of AP was $0.118 \%$ (brown leaves) at St-3 during the dry season and lowest was $0.04 \%$ (green leaves) at St-3 during the wet season. The AP contents were $0.112 \%$ (St-1), $0.107 \%$ (St-2), 0.012\% (St-3) and $0.106 \%$ (St-4) in green leaves during dry season, while AP contents were $0.62 \%$ (St-1), $0.067 \%$ (St-2), 0.047\% (St3 ) and $0.78 \%$ (St-4) in wet season (Figure 12). In brown leaves of Koroch plant, AP contents were $0.104,0.092,0.109$ and $0.096 \%$ during dry season, and $0.041,0.043,0.04$ and $0.054 \%$ during wet season at St-1, St-2, St-3, and St-4, respectively. The AP contents in plant leaves were higher in dry season than wet season might be due to the high temperature in wet season, though the AP was higher in brown leaves than green.
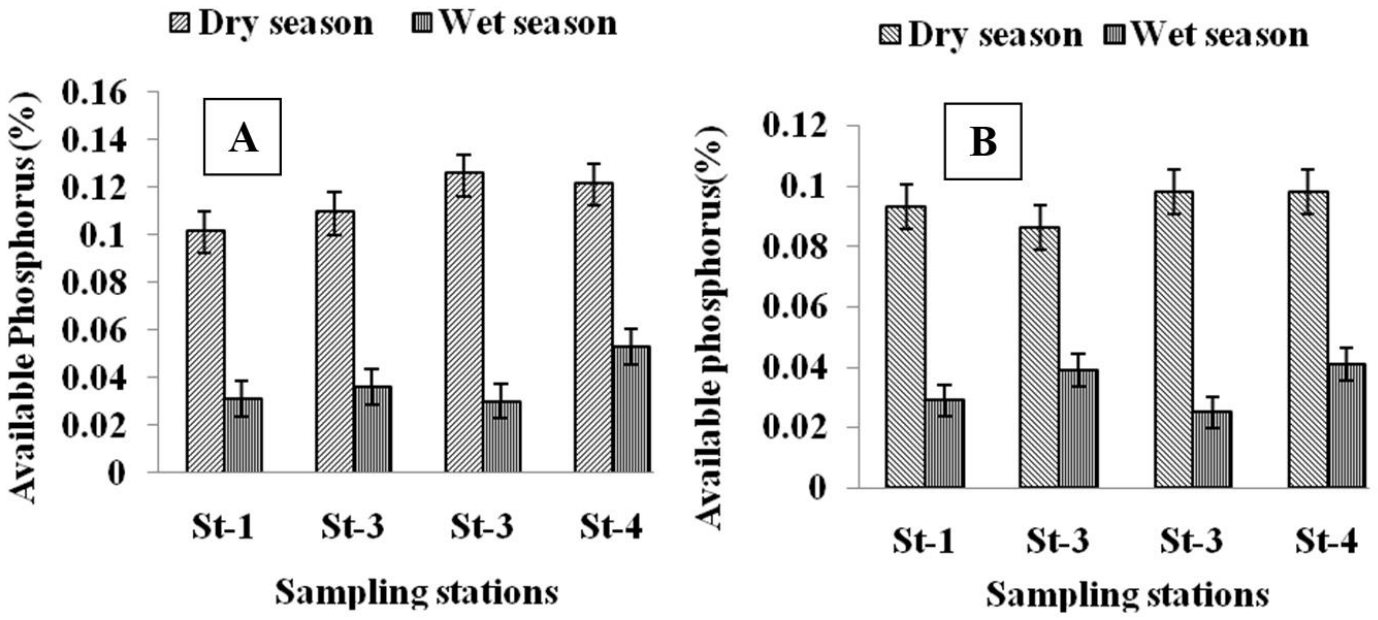

Figure 11. The AP in green (A) and brown (B) leaf of Hijal plant in different sampling season
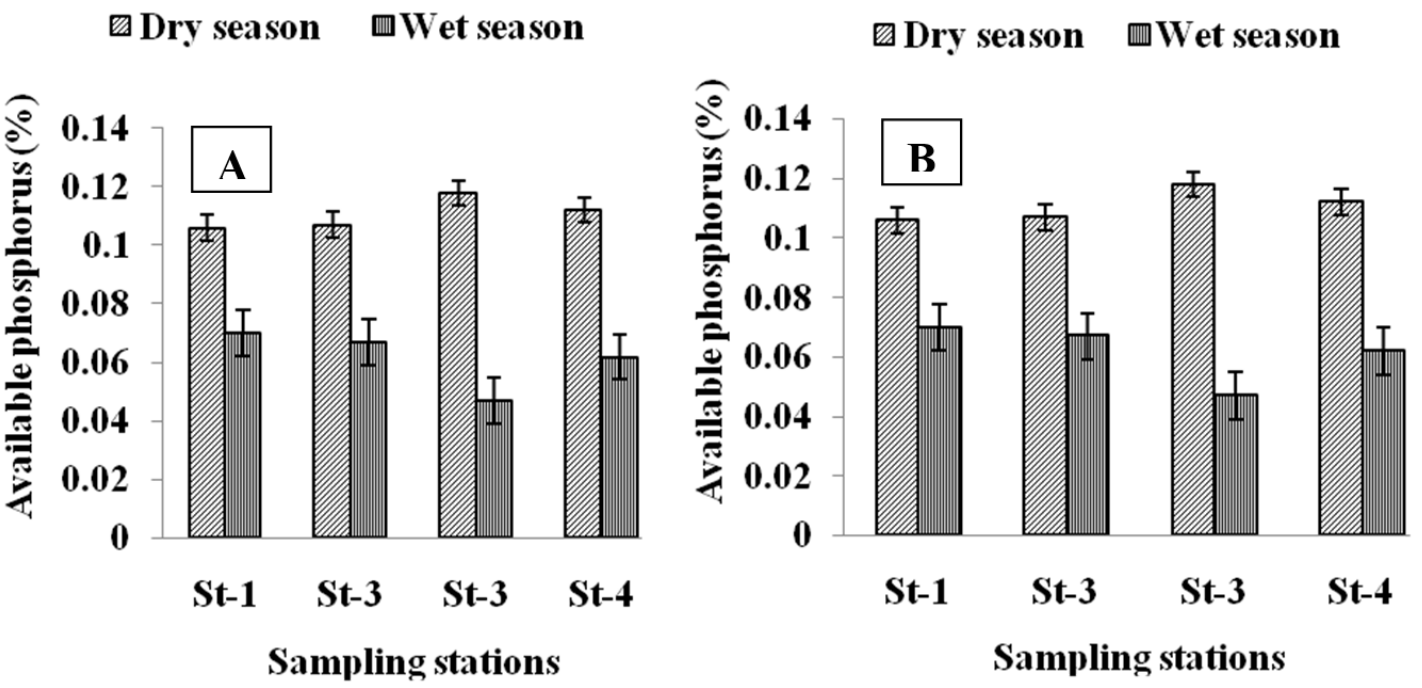

Figure 12. The AP in green (A) and brown (B) leaf of Koroch plant in different sampling season 
Doi: https://doi.org/10.33002/nr2581.6853.03014

Table 1: Correlations among nutrients in sediments, water and plant leaves

\begin{tabular}{|c|c|c|c|c|c|c|c|c|}
\hline & SP & SN & WP & WN & HLP & HLN & KLP & KLN \\
\hline SP & 1 & & & & & & & \\
\hline SN & -0.314 & 1 & & & & & & \\
\hline WP & -0.267 & $0.661^{* *}$ & 1 & & & & & \\
\hline WN & 0.285 & 0.497 & 0.241 & 1 & & & & \\
\hline HLP & $0.784 *$ & 0.295 & $0.647 *$ & $0.647 *$ & 1 & & & \\
\hline HLN & -0.319 & $0.883^{* *}$ & $0.842^{* *}$ & 0.361 & 0.500 & 1 & \\
\hline KLP & $0.840^{*}$ & $0.663^{* *}$ & 0.318 & 0.510 & 0.278 & 0.502 & 1 & \\
\hline KLN & -0.148 & $0.887^{* *}$ & $0.796^{* *}$ & 0.321 & 0.538 & $0.847 * *$ & 0.574 & 1 \\
\hline
\end{tabular}

*Correlation is significant at the 0.05 level and ** Correlation is significant at the 0.01 level (2tailed). $\mathrm{SP}=\mathrm{AP}$ in Sediments, $\mathrm{SN}=\mathrm{TN}$ in Sediments, WP=AP in Water, WN=TN in water, HLP= AP in the leaf of Hijal, HLN= TN in the leaf of Hijal, KLP=AP in the leaf of Koroch, KLN $=\mathrm{TN}$ in the leaf of Koroch.

This study found that there was a significant positive correlation between AP content of plants leave and AP content of water. In both Koroch and Hijal leaves, the amount of AP increased with the increased amount of AP in sediments. There was a positive statistical correlation between TN content of leaves of Hijal and TN content of water. This study found that the content of TN in the leaves of Koroch increased with the increasing of TN in the sediments and there was a strong positive statistical correlation between them. Study showed that there was a significant positive correlation between AP of plant leaves and AP of sediments. The AP in leaves of Hijal increased with the increase of AP in water and there was also a strong positive correlation between them. The content of AP in the leaves of Koroch increased with the increasing of AP in sediments and there was a strong positive statistical relationship between them. The vegetation responds positively to inorganic $\mathrm{N}\left(\mathrm{NH}_{4}-\mathrm{N}, \mathrm{NO}_{3}-\mathrm{N}\right)$ and $\mathrm{P}\left(\mathrm{PO}_{4}-\mathrm{P}\right)$ in surface water (Craft and Graham, 2007). The content of AP of plant leaves increased with the increase of the AP of sediments and also showed a significant positive correlation. The content of TN in the leaves of Hijal increased with the increase of AP in water. There was a strong positive statistical relationship between them. The content of TN in the leaf of Koroch also increased with the increase of TN in the sediments. The vegetation responds positively to available $\mathrm{N}$ and $\mathrm{P}$ in surface sediments (Craft and Graham, 2007).

\section{Conclusions}

Results of this study concluded that the sediments of the Ratargul Swamp forest were nutrientsenriched indicating that more input of external anthropogenic nutrient in turn may disturb the present ecological balance of this complex ecosystem. The amount of TN and AP in the water was higher in the wet season than dry season which might be due to the excessive use of nitrogen and phosphorous in the surrounding agricultural land. The average TOC in the plant leaves were higher in wet season than dry season, while the TN and AP in the plant leaves were higher during dry season than in the wet season. Thus, the study concluded that the amount of TN and AP in the plant leaves depended on the amounts of TN and AP in the sediments and water. Finally, the study pointed that aquatic environment of Ratargul swamp forest in terms of nutrients load is improvised with the changes of seasons. Thus, the study suggested that to maintain the rigorous and healthy natural ecosystem of the forest needed regular monitoring and management of the nutrient dynamics of the forest components. 
Doi: https://doi.org/10.33002/nr2581.6853.03014

\section{Acknowledgments}

Special appreciation to Mr. Rony Basak (Department of Geography and Environment, Shahjalal University of Science and Technology, Sylhet), Mr. Nuraalam Siddique (Department of Biotechnology, Bangabandu Sheikh Mujibur Rahman Agricultural University, Gazipur) and Mr. Md. Nahian (Department of ESRM, MBSTU) for their constructive advices and suggestions during the research work.

\section{References}

BFD (Bangladesh Forest Department) (2013). Annual Report, Ministry of Environment and Forest, Government of the People's Republic of Bangladesh, Dhaka.

Black, C.A. (1965). Methods of soil analysis: Part 2, American Society of Agronomy Inc. Madison, Wisconsin, USA, pp. 67.

Brown, S.L., Brinson, M.M. and A.E. Lugo (1979). Structure and function of riparian wetlands. In: Johnson RR, Cormick JE (eds.) Strategies for protection and management of flood plain wetlands and other riparian ecosystems. US Forest Survey General Technical Report W.O. 12. Washington DC, USA, pp: 17-31.

Choudhury, J.K., Biswas, S.R., Islam, M.S., Rahman, O. and Uddin, S.N. (2004). Biodiversity of Ratargul swamp forest, Sylhet. IUCN Bangladesh Country Office, Dhaka, Bangladesh, pp: 4-24.

Craft, C. and Casey, W.P. (2000). Sediments and nutrients accumulation in floodplain and depressional freshwater wetlands of Georgia, USA. The Society of Wetland Scientists, 20(2): 323-332. DOI: 10.1672/0277-5212(2000)020[0323: SANAIF] 2.0.CO; 2.

Craft, C., Krull, K. and Graham, S. (2007). Ecological indicator of nutrient enrichment freshwater wetland, Midwestern United States. Ecological Indicator, 7(1): 733-750. DOI: 10.1016/j.ecolind.2006.08.004.

De, A.K. (2010). Environmental Chemistry. $7^{\text {th }}$ edition. New Delhi: New Age Int. (P) Ltd., pp. 169-170.

Elser, J.J., Bracken, M.E.S., Cleland, E.E., Gruner, D.S. and Harpole, W.S. (2007). Global analysis of nitrogen and phosphorus limitation of primary producers in freshwater, marine and terrestrial ecosystems. Ecology Letter, 10: 1135-1142. DOI: 10.1111/j.14610248.2007.01113.x.

Gupta, N., Anthwal, A. and Bahuguna, A. (2006). Biodiversity of Mothronwala swamp, Doon valley, Uttaranchal. The Journal of American Science, 2(3): 33-40.

Hossain, M.G. and Bhuiyan, H.A.M. (2016). Spatial and temporal variations of organic matter contents and potential sediment nutrient index in the Sundarbans mangrove forest, Bangladesh. KSCE Journal of Civil Engineering, 20(1):163-174. DOI: 10.1007/s12205-0150333-0.

Iatrou, M., Papadopoulos, A., Papadopoulos, F., Dichala, O., Psoma, P. and Bountla, A. (2014). Determination of soil available phosphorus using the Olsen and Mehlich 3 methods for Greek soils having variable amounts of calcium carbonate. Communications in Soil Science and Plant Analysis, 45(16): 2207-2214. DOI: 10.1080/00103624.2014.911304

Islam, M.S., Islam, M.A., Sweety, N.A., Hossain, M.A.R. and Kabir, M.H. (2016). Assessment of aquatic faunal diversity in the Ratargul swamp forest at Sylhet in Bangladesh. Journal of Environmental Science and Natural Resources, 9(2): 51-64. DOI: 10.3329/jesnr.v9i2.32158. Jackson, M.L. (1985). Soil Chemical Analysis. Oaretic Hall of India Private Ltd., New Delhi, India. 
Manhas, R.K., Gautam, M.K. and Kumari, D. (2009). Plant diversity of a freshwater swamp of Doon valley, India. Journal of American Science, 5(4): 7-11.

Minar, M.H., Hossain, M.B. and Shamsuddin, M. (2013). Climate change and coastal zone of Bangladesh: vulnerability, resilience and adaptability. Middle-East Journal of Scientific Research, 13(1): 114-120.

Nahian, M., Islam, M.S., Kabir, M.H., Tusher, T.R. and Sultana, N. (2018). Seasonal variation of water quality in Gowain river near Ratargul swamp forest, Sylhet, Bangladesh. Grassroots Journal of Natural Resources, 1(1): 26-36. DOI: 10.33002/nr2581.6853.01013.

Omokhua, G.E. and Koyejo, A.O. (2008). Impact of deforestation on ecosystem: A case the freshwater swamp forest in Onne study of Niger delta region, Nigeria. Journal of Agricultural and Social Research, 8: 1-5. DOI: 10.4314/jasr.v8i2.43349.

Osaki, M., Ping, H.E., Takebe, M. and Shinan, T. (2003). Comparison of whole system of carbon and nitrogen accumulation between two maize hybrids differing in leaf senescence. Photosynthetica, 41(3): 399-405. DOI: 10.1023/B:PHOT.0000015464.27370.60.

Page, A.L., Miller, R.H. and Kenny, D.R. (1989). Methods of soil analysis: Part II. $2^{\text {nd }}$ Edition. American Society of Agronomy Inc., Wisconsin, USA, pp. 1203.

Piper, C.S. (1950). Soil and plant analysis. Hassel, Australia: Adelaide University Press, pp. 78.

Reich, P.B. and Oleksyn, J. (2004). Global patterns of plant leaf N and P in relation to temperature and latitude. Proceeding of National Academy of Science, 101: 11001-11006. DOI: 10.1073/pnas.0403588101.

Sharma, N. and Joshi, S.P. (2008). Comparative study of freshwater swamp of Doon valley. The Journal of American Science, 4(1): 7-10.

Shaw, K. (1959). Determination of organic carbon in soil and plant material. European Journal of Soil Science, 10(2): 316-326. DOI: 10.1111/j.1365-2389.1959.tb02353.x.

$\mathrm{Xu}, \mathrm{Y}$. and Chunjing, Z. (2015). Hydrological research progress in forest marsh ecosystem. In: International conference on agricultural, ecological and medical sciences (AEMS-2015), Thailand. 